BMJ Open Sport \& Exercise Medicine

\title{
Rethinking innovation and the role of stakeholder engagement in sport and exercise medicine
}

\author{
Sharief Hendricks (iD) $1,2,3$
}

To cite: Hendricks S. Rethinking innovation and the role of stakeholder engagement in sport and exercise medicine. BMJ Open Sport \& Exercise Medicine 2021;7:e001009. doi:10.1136/ bmjsem-2020-001009

\section{Check for updates}

(C) Author(s) (or their employer(s)) 2021. Re-use permitted under CC BY-NC. No commercial re-use. See rights and permissions. Published by BMJ.

${ }^{1}$ Division of Exercise Science and Sports Medicine, Department of Human Biology, University of Cape Town, Rondebosch, South Africa ${ }^{2}$ Carnegie Applied Rugby Research (CARR) centre, Institute for Sport, Physical Actvity and Leisure, Leeds Beckett University, Leeds, UK ${ }^{3}$ Health, Physical Activity, Lifestyle and Sport Research Centre, University of Cape Town, Cape Town, South Africa

Correspondence to Dr Sharief Hendricks; sharief.hendricks01@gmail.com

\section{ABSTRACT}

In sport and exercise medicine, increasing pressure to improve athlete health outcomes and performance with limited resources has prompted an emphasis on innovation. A key component to innovation is stakeholder participation and engagement, that is, the involvement of those affected by the outcomes, such as end users and actors (the person(s) performing the required actions/behaviour change), of the research process. Several research frameworks in sport and exercise medicine highly recommend stakeholder engagement as part of the research process. There are, however, different levels to how engaged a stakeholder can be in a research project, and this level of engagement may be dependent on the researchers' goals. Stakeholder engagement can be organised on a continuum based on the stakeholder's relationship to the research and how involved they are in the project's decision-making process. This continuum can be used as a rating scale to evaluate and monitor the degree of perceived stakeholder participation in a research project. There are different paths to innovation in research, which are interlinked, and ideas and knowledge flow between them. Considering the continuum of stakeholder engagement and paths to innovation, this article highlights how different research types require different degrees of stakeholder engagement.

\section{INTRODUCTION}

Innovation is a broad concept that can be defined as the successful implementation of a novel idea that creates value for some or all its stakeholders. ${ }^{1}$ In sport and exercise medicine, increasing pressure to improve athlete health outcomes and performance with limited resources has prompted an emphasis on innovation. ${ }^{23}$ A key component of innovation is stakeholder participation and engagement, that is, the involvement of those affected by the outcomes, such as end users and actors (the person(s) performing the required actions/ behaviour change), of the research process. ${ }^{4}$ Arguably, by involving stakeholders in the research process, research objectives will be more aligned to the stakeholders' needs and context, thereby increasing the likelihood of successful implementation. ${ }^{56}$ For this paper, the term stakeholders may include patients, athletes, target populations, practitioners,

\section{What is already known}

Innovation is a broad concept that can be defined as the successful implementation of a novel idea that creates value for some or all its stakeholders.

- In sport and exercise medicine, increasing pressure to improve athlete health outcomes and performance with limited resources has prompted an emphasis on innovation.

- A key component of innovation is stakeholder participation and engagement.

\section{What are the new findings}

- Stakeholder engagement can be organised on a continuum based on the stakeholder's relationship to the research and how involved they are in the project's decision-making process.

- This continuum can be used as a rating scale to evaluate and monitor the degree of perceived stakeholder participation in research projects.

- There are different paths to innovation in research, which are interlinked, and ideas and knowledge flow between them.

- Different types of research for innovation require different degrees of stakeholder engagement.

clinicians, policy makers or administrators, and a research outcome(s) is any finding(s), programme, product, practice or technology that benefits stakeholders and, ultimately, the health, welfare and performance of the athlete(s) or target population. In sport and exercise medicine, several research frameworks highly recommend stakeholder engagement as part of the research process. ${ }^{5-8}$ For example, in 2014, Verhagen $e t$ $a l$. described the knowledge transfer scheme to help bridge the gap between science and practice. $^{5}$ A key step in applying this framework is establishing a group of stakeholders (knowledge transfer group) to identify the problem, discuss the available evidence and develop the product/programme. ${ }^{5}$ There are, however, different levels to how engaged a stakeholder can be in a research project, 
and this level of engagement may be dependent on the researchers' goals. The aims of this viewpoint are to (1) describe the different levels of stakeholder engagement and offer potential ways to improve it; (2) describe the different paths to innovation; then, (3) considering the different levels of stakeholder engagement and paths to innovation, argue why the degree of stakeholder engagement depends on the type of research and its purpose.

\section{LEVELS OF STAKEHOLDER ENGAGEMENT}

Stakeholder engagement can be organised on a continuum based on the stakeholder's relationship to the research and how involved they are in the project's decision-making process. ${ }^{9-15}$ For the lowest level of engagement on the continuum, stakeholders' relationship to the research is 'on' or 'for', and their involvement is doing what the research project requires (ie, researchers make all the decisions). For the highest level, stakeholders' relationship to the research is 'by', and they are involved in all the decision-making on the project. This level of engagement is modelled on community development and empowerment, and described as the 'bottom-up' or the people-centred/patient-centred approach. ${ }^{121416}$ Midway between the two extreme levels of engagement is a moderate level of engagement where stakeholders' relationship to research is 'with' and collaborative in nature. At the moderate level of engagement, stakeholders contribute to the decision-making, although researchers still make the final call.

\section{ASSESSING STAKEHOLDER ENGAGEMENT}

Hendricks ${ }^{13}$ and others ${ }^{12}{ }^{15}$ have applied this continuum of stakeholder engagement to a 5-point rating scale which can be used to evaluate and monitor the degree of perceived stakeholder participation of research projects (figure 1). The rating scale offers a simple and practical measure to characterise the nature of stakeholder engagement within a project and has been used considerably in community health research. ${ }^{12} 1315$ Using the rating scale, stakeholders can provide their perceived level of engagement at different stages of the research process. For example, after a knowledge transfer group meeting to identify the problem, ${ }^{5}$ each stakeholder can rate their level of engagement in the problem identification process. If a particular stakeholder rated their engagement as low, the group could address it in the next meeting. In the ideal scenario, the person monitoring the engagement should be external to the project and should collect the perceived ratings of both the researcher(s) and stakeholders. The ratings could be from their perspective and that of others in the working group, which can be used to cross-check the consistency of the ratings. In cases where the researcher is also the practitioner, ${ }^{17}$ that is, where the researcher can also be considered a stakeholder that may potentially benefit from the research outcome(s), the researcher-practitioner will rate their engagement based on their primary role on the research project. At the end of the project, ratings can also be related to the research outcomes and for reporting purposes. For example, British Medical Journal (BMJ) journals, like BMJ Open Sport and Exercise Science, require authors to include a 'patient and public involvement statement' within their manuscript Method section. Instead of a statement, BMJ can use the aforementioned rating scale to ask authors to either rate their patients and public (stakeholders) engagement themselves or to submit stakeholder engagement ratings that were collected during the research project. This will help BMJ standardise the information and allow them to monitor the level of stakeholder engagement for all their submissions.

\section{PATHS TO INNOVATION}

There are different paths to innovation in research, and all these paths are interlinked. Fundamentally, research is inspired and driven to achieve two outcomes-improved

A

\begin{tabular}{ccccc}
\hline 1 & 2 & 3 & 4 & 5 \\
Very Low & Low & Moderate & High & Very High
\end{tabular}

B

\begin{tabular}{|c|c|c|}
\hline 1 & 3 & 5 \\
\hline $\begin{array}{l}\text { - Narrow participation } \\
\text { - Medical approach/Utilitarian models } \\
\text { - Mobilisation } \\
\text { - Professional makes all the decisions } \\
\text { 'on/for' stakeholders }\end{array}$ & $\begin{array}{l}\text { - Medium participation } \\
\text { - Health services approach } \\
\text { - Collaborative } \\
\text { - Stakeholders contribute, } \\
\text { professionals make final decisions } \\
\text { - Relationship to research - } \\
\text { 'with' stakeholders }\end{array}$ & $\begin{array}{l}\text { - Wide participation } \\
\text { - Community development approach } \\
\text { - Empowerment } \\
\text { - All stakeholders make decisions } \\
\text { - Relationship to research - } \\
\text { 'by' stakeholders }\end{array}$ \\
\hline
\end{tabular}

Figure 1 (A) Perceived level of participation Visual Analogue Rating Scale. (B) Participation rating scale interpretation (reproduced with permission). ${ }^{13}$ 


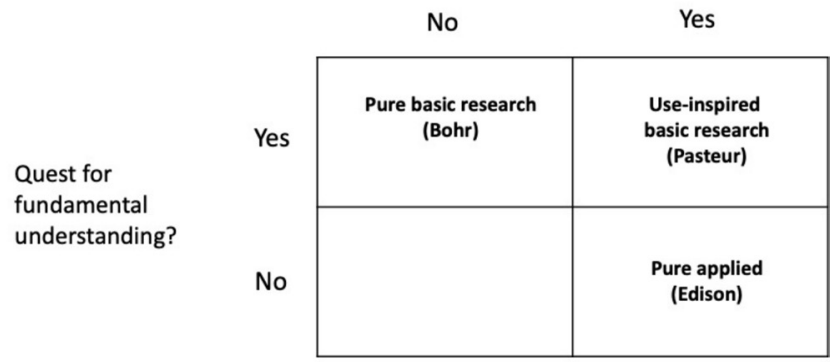

Figure 2 Quadrant model for scientific research (reproduced with permission). ${ }^{18}$

understanding of 'how it works' (basic research) and usefulness ('Can we use it in practice?') (applied research). ${ }^{18}$ The outcomes are not mutually exclusive, and a study can aim to improve our understanding of a subject and consider its usability in practice. Studies of this nature, that is, with both aims in mind, are called use-inspired basic research. To illustrate the relationship between these types of research, Stokes placed them in a $2 \times 2$ table-what is now famously known as Pasteur's quadrant (figure 2). ${ }^{18}$ The quadrant was for heuristic purposes only; however, to connect the cells, the literature has erroneously indicated the direction in which knowledge flows between them. ${ }^{19}$

Stokes reveals the directional and dynamic flow of ideas and knowledge between research types and outcomes (figure 3). ${ }^{18}$ The model shows how basic research may improve our current understanding of a particular topic or subject without considering its application. In sport and exercise medicine, for example, basic research may be studying skeletal muscle adaptation. Likewise, applied research may improve practice without improving our understanding. In sport and exercise medicine, this may be, for example, studying the effectiveness and implementation of a training programme to reduce the risk of tackle injuries in rugby. However, basic research and applied research can strongly influence each other in either direction, with use-inspired basic research playing the linking role. ${ }^{18}$ With that said, use-inspired research may also independently increase our fundamental understanding or produce real-world applications. Staying with our example, if we understand the physiology behind how skeletal muscle adapts to different stimuli, we can design and develop better training programmes. Use-inspired

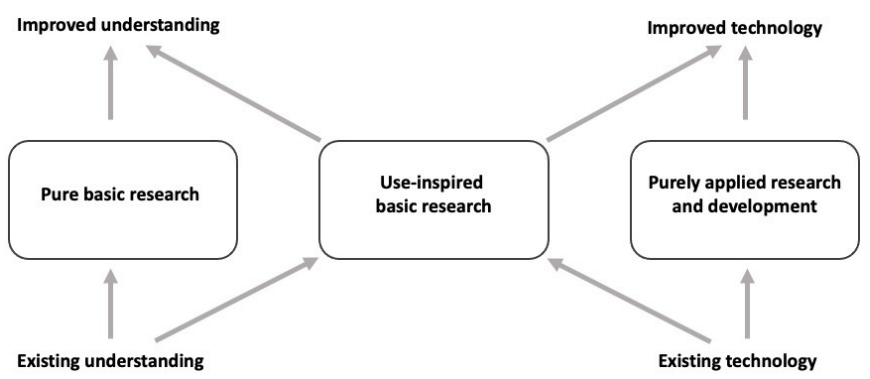

Figure 3 Dynamic model (reproduced with permission). ${ }^{18}$ research may include exploratory studies, efficacy studies and experiential studies. As such, it is more likely to be systematic in its approach, apply traditional study designs and have study-specific outcome variables. Because of this systematic approach and design, the value of use-inspired research, especially to practice, is not immediately appreciated. From an innovation perspective, though, unlike applied research that may be constrained to context and time, use-inspired research has the freedom to explore and experiment. Research that aims for both understanding and usability may lead to a paradigm shift in our thinking of a particular topic, discover a new direction of research or increase the potential for a breakthrough innovation.

\section{WHY STAKEHOLDER ENGAGEMENT DOES NOT HAVE TO BE 'HIGH' FOR A PROJECT TO BE INNOVATIVE}

Considering the continuum of engagement levels in figure 1 and the dynamical model for knowledge and innovation in figure 3, this articles highlights that the different types of research require different degrees of stakeholder engagement to achieve the desired research outcomes (figure 4). In other words, the level of engagement on a project depends on the type of research and its purpose. For applied research to be successful, stakeholder engagement needs to be high; context needs to be understood, along with implementation barriers/facilitators. For use-inspired research, researchers work with the stakeholders, and the project is collaborative. While stakeholders still provide valuable input, the researcher makes the final decisions on the study design and outcome measurements. For basic research, stakeholder engagement may still occur, but this will be at a very low level, for example, obtaining participant samples during testing. It is also worth noting that the innovation produced from each research type may also benefit the practice of the research itself across the different research types. For example, the outcome of use-inspired research may be a tool that accurately measures tackling technique-this outcome will improve practice, but at the same time, it can also be used to test players for research studies.

\section{CONCLUSION}

There is increasing pressure to improve athlete health outcomes and performance with limited resources. This has prompted an emphasis on innovation. A key component to innovation in health research is stakeholder participation and engagement, that is, the involvement of end users and actors in the research process who may be affected by the research outcomes. In sport and exercise medicine, several research frameworks highly recommend stakeholder engagement as part of the research process. Stakeholder engagement can be organised on a continuum based on the stakeholder's relationship to the research and how involved they are in the project's decision-making process. This continuum can be used as a rating scale to evaluate and monitor the degree of perceived stakeholder participation in research projects. 


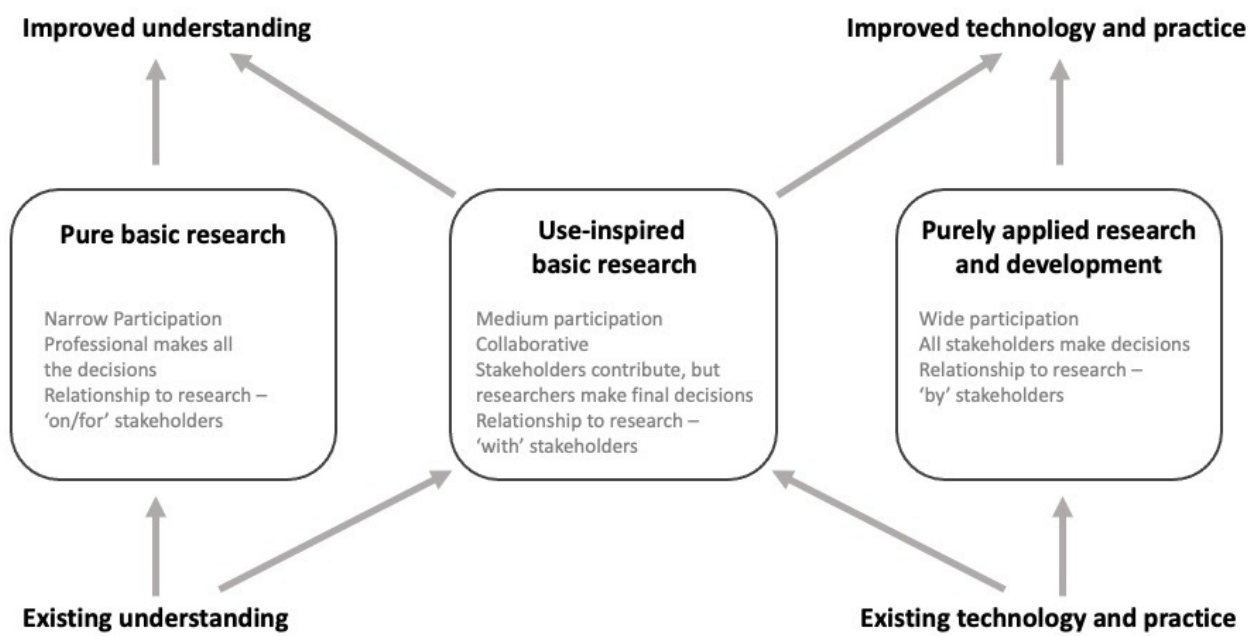

Figure 4 Dynamic model for innovation and stakeholder engagement.

There are different paths to innovation in research, which are interlinked, and ideas and knowledge flow between them. Considering the continuum of stakeholder engagement and paths to innovation, this article highlights how different research types require different degrees of stakeholder engagement.

\section{Twitter Sharief Hendricks @Sharief_H}

Contributors SH is the sole author of the article.

Funding The authors have not declared a specific grant for this research from any funding agency in the public, commercial or not-for-profit sectors.

Competing interests None declared.

Patient consent for publication Not required.

Provenance and peer review Not commissioned; externally peer reviewed.

Open access This is an open access article distributed in accordance with the Creative Commons Attribution Non Commercial (CC BY-NC 4.0) license, which permits others to distribute, remix, adapt, build upon this work non-commercially, and license their derivative works on different terms, provided the original work is properly cited, appropriate credit is given, any changes made indicated, and the use is non-commercial. See: http://creativecommons.org/licenses/by-nc/4.0/.

ORCID iD

Sharief Hendricks http://orcid.org/0000-0002-3416-6266

\section{REFERENCES}

1 Varkey P, Horne A, Bennet KE. Innovation in health care: a primer. Am J Med Qual 2008;23:382-8.

2 Ramírez-López C, Till K, Boyd A, et al. Coopetition: cooperation among competitors to enhance applied research and drive innovation in elite sport. Br J Sports Med 2020;55:522-3.

3 Speed CA, Roberts WO. Innovation in high-performance sports medicine. Br J Sports Med 2011:45:949-51.

4 Bowen DJ, Hyams T, Goodman M, et al. Systematic review of quantitative measures of Stakeholder engagement. Clin Trans/ Sci 2017:10:314-36.
5 Verhagen E, Voogt N, Bruinsma A, et al. A knowledge transfer scheme to bridge the gap between science and practice: an integration of existing research frameworks into a tool for practice. Br J Sports Med 2014;48:698-701.

6 Finch CF, Talpey S, Bradshaw A, et al. Research priorities of international sporting federations and the IOC research centres. $B M J$ Open Sport Exerc Med 2016;2:e000168.

7 Owoeye OBA, Rauvola RS, Brownson RC. Dissemination and implementation research in sports and exercise medicine and sports physical therapy: translating evidence to practice and policy. BMJ Open Sport Exerc Med 2020;6:e000974.

8 Ahmed OH, Defoe J, West LR, et al. Creating the dream team: introducing participatory sports and exercise medicine via 'Patient Voices'. Br J Sports Med 2018;52:1547-8.

9 Arnstein S. A ladder of participation in the USA. J R Town Plan Inst 1971;16:176-82.

10 Cornwall A, De Koning K. Towards participatory practice: participatory rural appraisal (PRA) and the participatory process. In: De Koning K, Marion M, eds. Participatory research in health. London: Zed Books Ltd, 1996.

11 Rifkin SB, Lewando-Hundt G, Draper A. Participatory approaches in health promotion and health planning: a literature review. London: Health Development Agency, 2000.

12 Draper AK, Hewitt G, Rifkin S. Chasing the dragon: developing indicators for the assessment of community participation in health programmes. Soc Sci Med 2010;71:1102-9.

13 Hendricks S, Conrad N, Douglas TS, et al. A modified stakeholder participation assessment framework for design thinking in health innovation. Healthc 2018;6:191-6.

14 Rifkin SB. Paradigms lost: toward a new understanding of community participation in health programmes. Acta Trop 1996;61:79-92.

15 Rifkin SB, Muller F, Bichmann W. Primary health care: on measuring participation. Soc Sci Med 1988;26:931-40.

16 Morgan LM. Community participation in health: perpetual allure, persistent challenge. Health Policy Plan 2001;16:221-30.

17 Jones B, Till K, Emmonds S, et al. Accessing off-field brains in sport; an applied research model to develop practice. Br J Sports Med 2019;53:791-3

18 Stokes DE. Pasteur's quadrant: Basic science and technological innovation. Washington DC: Brookings Institution Press, 1997.

19 Klahr D. Learning sciences research and Pasteur's quadrant. $J$ Learn Sci 2019;28:153-9. 